\title{
Traditional Mask Made From Mangosteen Peel Extract (Garcinia Mangostana L) As Pimply Skinface Treatment
}

\author{
Sri Dwiyanti, Siti Sulandjari \\ Department of Home Economics \\ Universitas Negeri Surabaya \\ Surabaya, Indonesia \\ sridwiyanti@unesa.ac.id
}

\begin{abstract}
Pimply skin is naturally experienced in teenage ages and becomes problem for their look. Pimples occur due to the accumulation of riddance in the skin pores into the growth of bacteria. Acne can cause cells damage in the area, so it needs treatments which use substances that kill the bacteria, while restoring a healthy skin. Extract xanthones from mangosteen rind is a substance that can reduce or even prevent the effects of bacterial activity as well as anti-oxidants .This study aimed to develop natural material treatment from xanthones as traditional mask for acne skin care facial in form of combining mangosteen peel extract and bengkoang (Pachyrus Erosus) starch mask. The result proof that $80 \%, 100 \%$, mangosteen extract can reduce acne.
\end{abstract}

Keywords-xanthone extract; pimply faced natural skin care material

\section{INTRODUCTION}

This research aims to develop a natural care ingredients (natural tenderizer) of xanthones, vitamins and antibacterial mangosteen peel in the form of a mixture of liquid extract with bengkoang starch which is applied to skin breakouts. The basic idea of this research develops from the acne skin problem experienced by many people with oily and normal skin types.

Specific targets would be achieved in this study are: 1) Obtaining a sample test results xanthones mangosteen peel extract (levels of xanthones, anti-bacterial activity) to determine the extract xanthones resistance with alcohol solvent; 2) discovering effect of comparison of mangosteen peel extract and bengkoang starch mask to the results of the healing acne for normal and oily skin; 3) Obtaining a formula that produces healing acne mask for normal and oily skin.

\section{METHODS}

This research method is experimental research with free variable is skin type, percentage of mangosteen skin extract, and frequency of mask of mangosteen skin mask. The skin type applied mask is the type of oily skin and normal skin. Percentage of mangosteen peel extract in mixture of mangosteen skin extract and bengkuang starch used were $60 \%, 80 \%$, and $100 \%$. The frequency of giving the mask is $3 \mathrm{x}$ and $5 \mathrm{x}$ and the dependent variable is the result of healing of acne on the oily facial skin which includes the production of oil on the facial skin is reduced, the pores of the face shrink, the acne deflated, the acne dries, the acne turns into dead and raised skin, and the brightness of the skin face. The sample amounted to 24 people with details of 12 people with normal facial types and 12 people with oily facial types. Variable control of mask making time, acne type, mask treatment time, age of acne facial skin, ingredients used (other than mangosteen skin extract and bengkuang starch), tools used mask, mask application on facial skin, mask application location, and long mask application.

\section{RESULTS AND DISCUSSION}

Acne is a blockage with inflammation in the ducts of the skin's oil glands, so that the secretion of skin oil is blocked, enlarged, dries, and becomes contents. Acne often occurs in adolescents caused by hormonal changes in adolescence. Eliminating acne can not be done just by washing the face, but require treatment in order to stop bacterial activity. The presence of acne often cause pain, cause discomfort and disrupt the appearance for the patient. Acne facial skin requires treatment to return to health, not pain, discomfort and disrupt the appearance of the patient. Acne healing can be done using active ingredients that can be obtained from nature.

Some groups of active ingredients for acne healing are: 1) antiseptic material, serves to prevent or kill bacteria that will infect skin pores; 2) keratolitik materials, serves to destroy the layer of skin that covers acne so that the contents of acne easily contact with the active ingredient; 3) acne dryers; 4) anti-pruritic ingredients, serves to prevent the onset of itching on acne and prevent the occurrence of infection in acne; 5) campora, serves to mengbergeringkan acne, reduce oil on the skin, and give a sense of fresh; and 6) alantoin, serves to stimulate the growth of new skin cells to prevent acne scars (pockmarks), as thickening agents, dyes, and fragrances.

Xanthone is a collection of bioactive compounds that have anti-inflammatory properties, prevent gloom, anti- 
aging, remove toxins and eliminate the effects of free radicals, killing germs, killing fungi, and repair the skin.

\section{A. Phase I}

The endurance test to mangosteen peel extract mask is by keeping it at room temperature and refrigerator. The test is done every two weeks for 6 times (week 12). Laboratory tests have been conducted on the microorganism growth stocks stored in two different places (room temperature and cooling temperature) each 2 samples.

Measurement on week two to week twelve the average number of microbes on the stocks stored at refrigeration temperatures lower than stock at room temperature. The average number of microbes from week two until the week 12 is increasing. The difference apparently between measurements on 2 nd week to 12 th week. It reaches almost twice to three times as much. Referring SNI Cosmetics Masks number of microbes that allowed in cosmetics is $<10^{4}$, then the durability of the mangosteen peel mask within 12 weeks of storage both on the coolant temperature and the room temperature can still be accepted and used.

Chong, ye mun [1] states that the efficacy of mangosteen peel extracts (100 and $200 \mathrm{ppm}$ ) in stabilizing sunflower oil tested under accelerated storage $\left(65^{\circ} \mathrm{C}\right)$ for a period of 24 days. Thus, it is suggested that mangosteen peel extract may be used as a potential source of natural antioxidants in the application of food industry to suppress lipid oxidation.

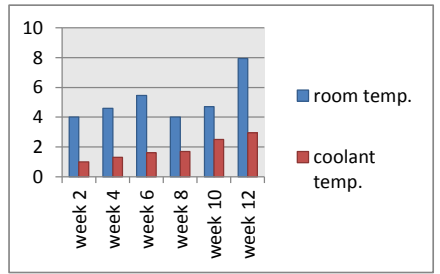

Fig. 1. Average Comparison Number of Microbes per 2 weeks

\section{B. Phase II}

Face masks test treatment is done on 24 samples of patients with oily skin with acne and normal face skin that given treatment different percent of mangosteen peel extract, and observes it after three times and five times. 24 respondents are grouped by objective data analysis, these are:

1. The group of respondents based skin types

a. Oily skin sample group consists of 12 samples, are observed after three times and five times treatment. b. Normal skin sample group consists of 12 samples are observed after three times and five times treatment.

2. Sample Groups based on the percent of mangosteen peel extract with yam starch to the mask

a. Mangosteen peel extract $60 \%$ with yam starch $40 \%$ consists of 8 samples are observed after three times and five times treatment.

b. Mangosteen peel extract $80 \%$ with yam starch $20 \%$ consists of 8 samples, are observed after three times and five times treatment.

c. Mangosteen peel extract $100 \%$, consists of 8 samples are observed after three times and five times treatment.

3. Sample group based on skin type and percent of mangosteen peel extract

a. Oily skin, mangosteen peel extract $60 \%=4$ (four) samples, are observed after three times and five times treatment.

b. Oily skin, mangosteen peel extract $80 \%=4$ (four) samples, were observed after three times and five times treatment.

c. Oily skin, mangosteen peel extract $100 \%=4$ (four) samples, were observed after three times and five times treatment.

d. Normal skin, mangosteen peel extract $60 \%=4$ (four) samples, were observed after three times and five times treatment

e. Normal skin, mangosteen peel extract $80 \%=4$ (four) samples, were observed after three times and five times treatment.

f. Normal skin, mangosteen peel extract $100 \%=4$ (four) samples, were observed after three times and five times treatment.

The data is presented in bar chart that includes oil production (figure 2), the size of the pores (figure 3), acne deflated (figure 4), acne dried up (figure 5), acne becomes dead skin and lift (figure 6), and brightness skin face (figure $7)$.

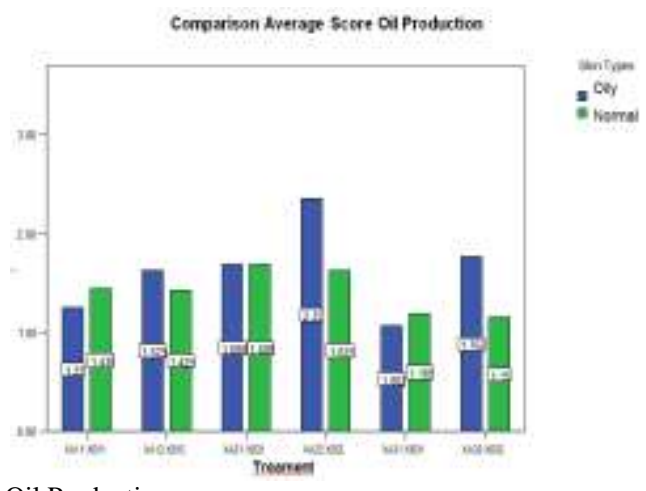

Fig. 2. Oil Production 


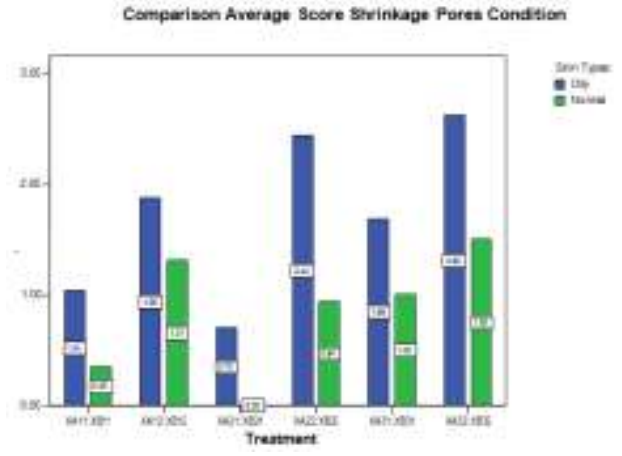

Fig. 3. Shrinkage Pores Condition

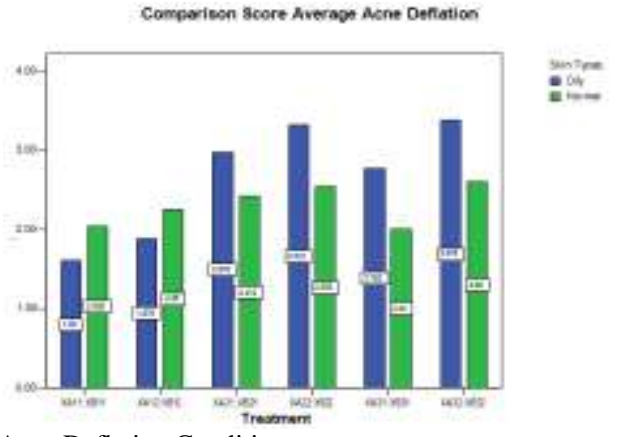

Fig. 4. Acne Deflation Condition

Comparison Average score Acne Dries up

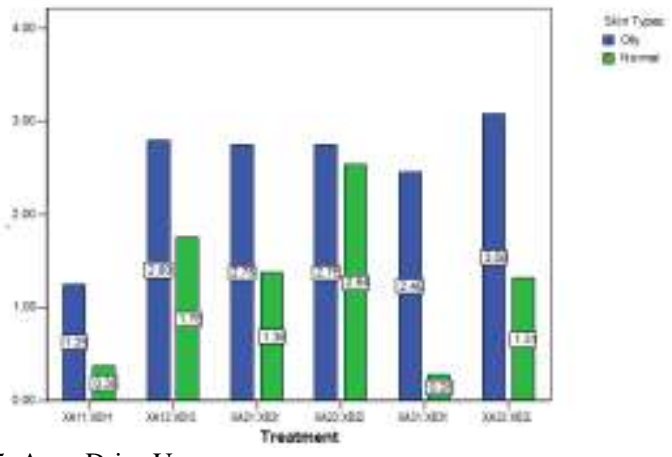

Fig.5. Acne Dries Up

Gomperison Aversge Scert Brighteness skintace

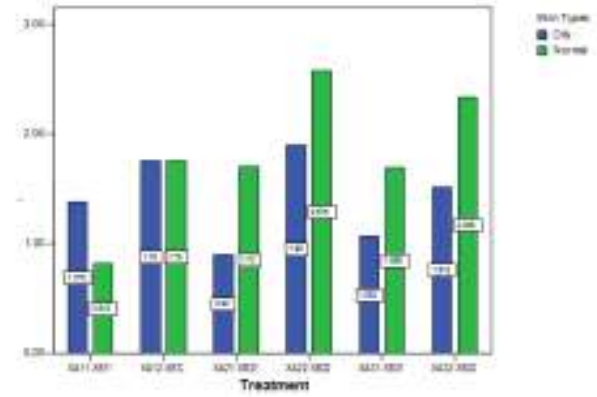

Fig. 6. Brightness Skinface
Camparison Average seore Acne Uplitted

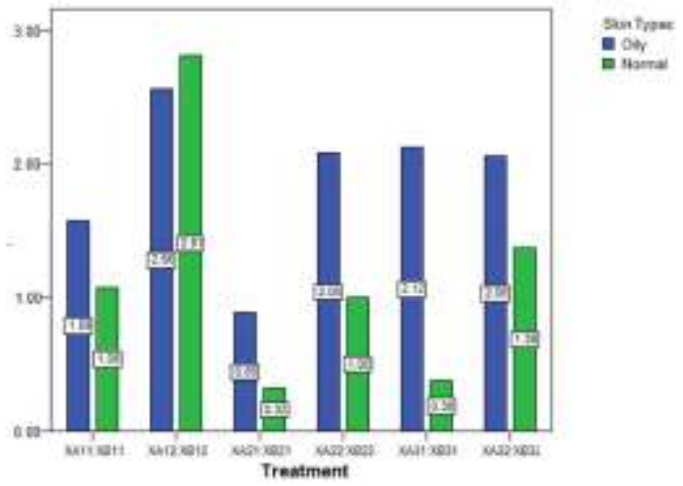

Diagram 5. Acne Dries up Condition Fig.7. Acne Uplifted

The influence that occurs on the test results of using the mask of mangosteen peel extract and yam starch treatment on oily skin and normal skin, with the percent of mangosteen peel extract $60 \%, 80 \%$ and $100 \%$, and three times and five times frequency adduction are as follow.

1. The effect of the interaction of skin type, percent mangosteen peel extract, and frequency of adduction..

a. From the descriptive and statistical analysis indicated that there is a tendency Interaction skin type, the percentage of mangosteen peel extract usage, and frequency of adduction has a tendency to give effect. The tendency impact of interactions between oily skin, use of mangosteen peel extract $100 \%$, and frequency five times adduction is the downsizing of the pores, acne deflation, and acne dried up. The tendency impact of interactions between oily skin, mangosteen peel extract $80 \%$ usage, and five times frequency adduction is against the reduction in skin oil production. The tendency of the interaction effect between normal skin types, the use of mangosteen peel extract $60 \%$, and five times frequency adduction to acne and it turns to dead skin and lifted. The tendency of the interaction effect between normal skin types, the use of mangosteen peel extract $80 \%$, and the five times frequency of adduction to the brightness of the skin. Those effects are marked by highest average score.

b. Skin type indicates the liabilty the effect on oily skin. The influence includes downsizing pores, acne deflated, and acne dried up. In normal skin types the effect to the acne is lifted and brightness.

c. The percentage usage of mangosteen peel extract has tendency give an impact. The use of mangosteen peel extract $80 \%$ is giving an effect to decreasing oil production, deflate acne, and acne dried up, and skin brightness. The usage of mangosteen peel extract $100 \%$ is giving an effect to downsizing skin pores and acne dried up. While the usage of mangosteen peel extract $60 \%$ makes acne lifted up. 
These results are accordance with [2] Bundeesomchok which states that The results support the potential use of ethyl lactate, DMC, MeTHF, and ethanol as alternative green solvents for the preparation of $\alpha$-mangostin extracts.

[3] Putra which states that the mangosteen peel is a natural way that is utilized to overcome the inflammation, showing that the xanthones in mangosteen peel has antiinflammatory properties. Xanthones dissolved by the solvent either through the use of alcohol, required a certain amount. Generally indicated that xanthon contained in the use of $80 \%$ extract of mangosteen peel has been able to demonstrate antiinflammatory activity.

[4] Tjahjani states that Many diseases correlate with antioxidant deficiencies. Garcinia mangostana L rind (GMR) belong to waste product, contains xanthones which are antioxidant compounds. The study was to determine antioxidant properties of its ethanolic extract, hexane, ethylacetate, butanol, and water fractions in DPPH scavengingactivity, level of SOD and total antioxidant (TAS) compared against $\alpha$-mangostin. Extract and all of these fractions had high DPPH trapping activity while $\alpha$-mangostin had low activity. Level of SOD was highest in GMR water fraction while TAS level was highest in GMR ethylacetate fraction. It was concluded that GMR products had potential antioxidant properties

2. The results of the statistical analysis of variable influence skin type test, percentage use mangosteen peel extract, and frequency given of the mask treatment outcomes as follows:

a. Interaction skin type, percentage use of mangosteen peel extract, and frequency given did not affect the reduction in oil production, reduction pores, acne deflated, dries pimples, acne lifted, and the skin brightness.

b. Type of skin influence on shrinkage pores and acne dried up

c. Percentage of usage mangosteen peel extract effects on oil reduction, downsizing of the pores, and acne deflation.

d. Frequency of largess is influenced to shrink pores, pimples dries, acne lifted, and skin brightness

[5] Chomnawang (401:207) states that the activity of Thai medicinal plants on inflammation caused by Propionibacterium acnes in terms of free radical scavenging and cytokine reducing properties. $P$. acnes have been recognized as pus-forming bacteria triggering an inflammation in acne. showed that Garcinia mangostana possessed the most significant antioxidant activity and reduced reactive oxygen species production. Houttuynia cordata, Eupatorium odoratum, and Senna alata had a moderate antioxidant effect. In addition, Garcinia mangostana was highly effective in scavenging free radicals and was able to suppress the production of proinflammatory cytokines. This study has identified the promising source of anti-inflammatory agent which could be useful in treatment of acne vulgaris.
3. Duncan test results showed that the average score as follows:

a. For the condition of oil on face, the highest score average is generated by treatment of the mangosteen peel extract $80 \%$ mask.

b. For the condition of shrink pores, , the highest score average is generated by treatment of the mask from the useing of mangosteen peel extract $100 \%$ or largess frequency $5 \mathrm{x}$ and occurs on oily skin.

c. For acne condition deflated, the highest score average is generated by treatment of the mask from the use of mangosteen peel extract $80 \%$.

d. For the condition of acne dries, the highest score average is produced on oily skin or largess frequency $5 x$.

e. For the condition acne turns to dead skin and uplifted, the highest score is generated at largess frequency $5 \mathrm{x}$.

f. For the skin brightness, the highest score is produced at largess frequency $5 \mathrm{x}$

Related to the results [6] Azimi (1306: 2012) states that Studies on cell lines revealed that flavonoid, alkaloid, essential oil, phenol and phenolic compound, tannin, xanthone and xanthone derivative, and the bisnaphthquione derivative are effective in treatment of acne. Animal studies showed that diterpene acid, phenylpropanoid glycosides, acteoside and flavonoids have anti-inflammatory activity. Eleven human studies revealed thatCamellia sinensis has $5 \alpha$-reductase inhibitory and anti-inflammatory activities. Also anti-bacterial effect was shown by oleoresin of Commiphora mukul.

[7] Pothitirat (442: 2009), states that Contents of bioactive components, free radical scavenging and anti-acne producing bacteria activities of young and mature fruit rind extracts of mangosteen were compared. The young fruit rind extract contained significantly higher contents of phenolics and tannins and promoted higher free radical scavenging activity than the mature fruit rind extract, while the later extract contained higher contents of flavonoids and $\alpha$ mangostin xanthone and gave higher anti-acne producing bacteria activity than the young fruit rind extract. Thus, the young and mature stages of mangosteen fruit rind should be beneficial for further development of antioxidant and anti-acne pharmaceutical preparations, respectively.

[8] Putra (19) also states that, xanthones mangosteen peel acts as an anti-inflammatory, relaxation, anti-aging, antioxidant, antiviral (kills germs), anti-biotic, anti-fungal. Meanwhile, yam starch function is whitenning skin, getting rid of black spots, an antidote to dispose of sweat, inhibit the aging process, healing ulcers, eczema and beautify overcome eye bags.

The more higher percentage of mangosteen peel extract lead content of xanthones higher and give effect on the reduction of oil production, narrowing of pores, and drying acne. The mechanism function using mangosteen peel extract at the first will reduce oil production in the skin. To help 
diminution oily skin pores need high mangosteen peel extract $(100 \%)$, and it will no effect on the brightness of the skin.

Uplifted of acne in normal skin does not require a high amount of extract, but it requires a high frequency. In normal skin, acne skin dries out more quickly because of the production fat skin is low. With $60 \%$ mangosteen peel extract nad $5 \mathrm{x}$ frequency can already be raised pimples. This is also shown in the usage of higher mangosteen peel extract $(80 \%)$ in normal skin with frequency $5 x$, showing a tendency to produce skin brightness.

[9] Trubus (2011: 9) states function the content of mangosteen peel as an active substance that can be used for skin beauty face which one is an excellent antioxidant properties to prevent premature aging and cure acne. Yam starch function as an adhesive and as an anti-bacterial in the mask. Yam function according to Putra (2012: 35) is as whitening skin, removing dark spots, an antidote to sweat, inhibit the aging process, healing ulcers (anti-bacterial), overcoming eczema, beautify eyelids. Related to the active substance content and function, the contents of mangosteen peel combining $80 \%$ mangosteen extract peel and $20 \%$ yam starch that given five times may effected to the reduction amount of oil production and acne deflate especially on oily skin. While the provision of mangosteen peel extract $100 \%$ influence on the downsizing of the pores.

Based on the analysis description above can be summarized, that review of percentage using mangosteen peel extract that gives effect is the use of $80 \%$. Review from the frequency with which gives more effect is five times. While from the skin that shows more affected by the use of mangosteen peel extract is oily skin. So the best mask is a mask that contains $80 \%$ of mangosteen peel extract, given $5 \mathrm{x}$ and applied on oily skin.

\section{CONCLUSION}

From the results of data analysis can be formulated conclusions, durability mask stock of mangosteen peel extract on the coolant temperature better than room temperature. Storage for 12 weeks still showed the number of microbes that can still be accepted. Interaction skin type and percentage of mangosteen peel extract usage has no effect on the reduction of oil, downsizing pores, acne deflated, dries pimples, acne lifted, and brightness skinface. Type of skin effects on shrinkage pores and acne dried up. Usage Percentage xanthones mangosteen rind extract effect on reducing skin oil , pore reduction, and acne deflate. The best results for oily skin face condition the highest score average is generated from mangosteen peel extract $80 \%$ mask treatment. For the condition with pores shrink the highest score average is generated from mangosteen peel extract $100 \%$ mask treatment. For condition with acne deflated the highest score average is generated from mangosteen peel extract $80 \%$ and $100 \%$ mask treatment. For the condition of acne dries, the highest score average produced on oily skin.

\section{ACKNOWLEDGEMENT}

Special Gratitude and Appreciation to Rector Unesa Prof. Drs Warsono, M.Pd, who give chance to us to develop our knowledge, Head of The Institute for Research and Community Service Unesa Prof. Dr. Wayan Susila, MT, who entrusting us to hold this research.

\section{REFERENCES}

[1] Chong, Ye Mun. Antioxidant efficacy of mangosteen (Garcinia Mangostana Linn) peel extracts in Sunflower Oil During Accelerated Storage. Food Bioscience, 2015. volume 12.

[2] Kunnitee Bundeesomchok, Aurore Filly, Njara Rakotomanomana, Pharkphoom Panichayupakaranant, Farid Chemat. 2016.Extraction of $\alpha$ Mangostin From Garcinia Mangostana L. Using Alternative Solvent: Computational Predictive and Experimental Studies. LWT-Food Science and Technology. Volume 65

[3] Putra, Sitiatava Rizema. 2012. Rahasia-Rahasia Keajaiban Kulit Buah Manggis untuk Kesehatan Harian \& Terapi Penyakit Berat. Yogyakarta: DIVA Press

[4] Susy Tjahjani, Wahyu Widowati, Khie Khiong, Adrian Suhendra, Rita Tjokropranoto. 2014.Antioxidant Properties Of Garcinia Mangostana L.(Mngosteen) Rind. Procedia Chemistry. Volume 13

[5] Mullika Traidej Chomnawang, Suvimol Surassmo, Veena S. Nukoolkarn, Wandee GritsanapanEffect Of Garcinia Mangostana On Iflamation Caused by Propionibacterium Acnes.Fitoterapia .2007. Volume 78, Issue 6

[6] Hanieh Azimi, Mehrnaz Fallah-Tafti, Ali Asghar Khakshur, Mohammad Abdollahi. A Review Of Phytotherapy Of Acne Vulgaris : Perspective Of New Pharmacological Treatments. Fitoterapia, 2012. Volume 83,

[7] Werayut Pothitirat, Mullika Traidej Chomnawang, Roongtawan Supabphol, Wandee Gritsanapan. Comparison Of Bioactive compounds Contents, Free Radical Scavenging And Anti-Acne Inducing Bacteria Activities Of Extracts From The Mangosteen Fruit Rind At Two Stages Of Maturity.Fitoterapia, 2009.volume 80.

[8] Putra, Sitiatava Rizema. 2012. Optimalkan Kesehatan Wajah dan Kulit dengan Bengkuang. Yogyakarta: Diva press.

[9] Redaksi Trubus. 2012. Kulit Manggis VS Penyakit Maut. Jakarta: Trubus Swadaya. 